\title{
A PESQUISA-INTERVENÇÃO COMO FORMA DE INSERÇÃO SOCIAL EM CONTEXTOS DE DESIGUALDADE: ARTE E IMAGINAÇÃO NA ESCOLA
}

A RESEARCH-INTERVENTION AS A PROCEDURE FOR SOCIAL INSERTION IN CONTEXTS OF INEQUALITY: ART AND IMAGINATION AT SCHOOL

LA INVESTIGACIÓN Y LA INTERVENCIÓN COMO FORMA DE INSERCIÓN SOCIAL EN
CONTEXTOS DE DESIGUALDAD: ARTE E IMAGINACIÓN EN LA ESCUELA

Vera Lucia Trevisan de Souza*

\begin{abstract}
RESUMO
Este artigo, de natureza teórico-reflexiva, tem como proposta refletir sobre a inserção social da pós-graduação em Psicologia em contextos de desigualdade. Seu objetivo é partilhar conhecimento e refletir sobre os contextos de desigualdade em que vivem muitos brasileiros, sobretudo aqueles das periferias de grandes cidades, e seu impacto no desenvolvimento dos sujeitos. Defende-se a educação escolarizada como promotora do desenvolvimento das funções psicológicas superiores e, logo, da imaginação e do desenvolvimento humano, como possibilidade de superação das condições materiais de vida de adolescentes em situação precária de vida. $\mathrm{O}$ texto se encerra com a apresentação de uma experiência desenvolvida com adolescentes pela via da Arte, que mobilizou a expressão dos afetos e a reflexão, investiu-se nas significações construídas nos espaços intersubjetivos, em que concorrem os processos imaginativos e afetivos, favorecendo a potência de ação e a produção de novos horizontes.
\end{abstract}

Palavras-chave: Pesquisa-intervenção. Desigualdade. Educação escolar. Desenvolvimento humano. Arte.

\begin{abstract}
This theoretical-reflexive article proposes to take into consideration the social insertion of postgraduate studies in Psychology in contexts of inequality. Its goal is to share knowledge and reflect on the contexts of inequality in which many Brazilians live, especially those on the its impact on the development of the subjects. School education is deemed as a promoter of the development of higher psychological functions and, hence, of imagination and human development, as a possibility of overcoming adolescents' low-income material living conditions. At the end, the text displays the presentation of an experience developed with adolescents through art, which mobilized the
\end{abstract}

* Professora doutora no Programa de Pós-Graduação e Psicologia na Pontifícia Universidade Católica de Campinas. E-mail: vera. trevisan@uol.com.br. 
expression of affection and reflection, invested in the meanings constructed in intersubjective spaces, in which the imaginative and affective processes compete, favoring the power the action and the production of new horizons.

Keywords: Research-intervention. Inequality. Schooling. Human development. Art.

\section{RESUMEN}

Este artículo teórico-reflexivo tiene como objetivo reflexionar sobre la inserción de los estudios de posgrado en Psicología en contextos de desigualdad. Su objetivo es compartir el conocimiento y reflexionar sobre los contextos de desigualdad en que viven muchos brasileños, en los alrededores de las grandes ciudades y, su impacto en el desarrollo individual. La educación escolar es defendida como promotora del desarrollo de funciones psicológicas superiores, de la imaginación y, el desarrollo humano, como una posibilidad de superar las condiciones materiales de la vida de los adolescentes en situaciones precarias de la vida. El texto finaliza con la presentación de una experiencia con adolescentes a través del arte, que moviliza la expresión de los afectos y la reflexión, que invierte en los significados construidos en los espacios intersubjetivos, en los que compiten los procesos imaginativos y afectivos, favoreciendo el poder de acción y la producción de nuevos horizontes.

Palabra clave: Investigación de intervención. Desigualdad. Educación escolar. Desarrollo humano. Arte.

\section{INTRODUÇÃO}

F Talar em inserção social na pós-graduação em Psicologia, tendo como perspectiva de atuação o enfrentamento da desigualdade, implica repensar a pesquisa e sua inserção em contextos que historicamente têm reunido grande parcela dos desiguais: a escola pública das grandes cidades, localizada em bairros/ regiōes periféricas. Também demanda refletir sobre o papel da pós-graduação para a superação da desigualdade e enfrentamento do sofrimento psicossocial. Ou seja, tarefa hercúlea a de refletir sobre temáticas complexas, perpassadas pelas dimensóes política, ética e econômica, sobretudo no momento atual, em que convivemos com expressóes de pensamentos que afirmam a necessidade de investimentos na produção de riquezas para alguns em detrimento de políticas e ou financiamento de pesquisas no campo das ciências, com maior depreciação das Ciências Humanas e Sociais.

Mas assumindo a perspectiva espinosiana de que os afetos relacionados a tristeza oprimem, impingindo em nós o padecimento, enquanto os afetos 
ligados a alegria produzem potência de ação capaz de nos libertar, ainda que momentaneamente, do jugo autoritário, sendo o conhecimento das causas a mola propulsora da mudança da afecção (Espinosa, 1957), parece-me sensato, neste momento, neste artigo, assumir que tem como objetivo partilhar conhecimento e refletir sobre as causas inadequadas ou adequadas e sobre seu poder na produção da desigualdade e do sofrimento psicossocial, como oportunidade para apresentar uma experiência em que a inserção social da Psicologia na pósgraduação produz horizontes como janelas de possibilidades para adolescentes do ensino médio de uma escola pública estadual situada na periferia de uma grande cidade e que convive com a violência, injustiça e falta de estrutura, aliás, condições características da ausência de um Estado que cedeu por completo às gerência e ingerência do mercado.

Este artigo se organiza em cinco tópicos que devem sustentar as ideias e acepções aqui apresentadas, derivadas da proposta de refletir sobre a inserção social da pós-graduação em Psicologia em contextos de desigualdade. Iniciase com a definição de inserção social e sua função na pós-graduação, tal como colocada no Plano Nacional de Pós-Graduação (PNPG) 2011-2020 (Brasil, 2010). Em seguida apresenta-se a pesquisa-intervenção como modalidade que possibilita a inserção da pós-graduação em Psicologia em contextos educativos. O terceiro tópico problematiza o conceito de desigualdade, com base em suas múltiplas determinações e trajetórias, tomado, portanto, em sua complexidade, e situa a escola como produtora de desigualdades. O quarto tópico defende o conhecimento escolarizado como promotor do desenvolvimento das funçóes psicológicas superiores e, logo, da imaginação e do desenvolvimento humano, como possibilidade de superação de algumas formas de desigualdade. $\mathrm{O}$ texto se encerra com a apresentação de uma experiência desenvolvida com adolescentes pela via da Arte, que mobiliza a expressão dos afetos e a reflexão, investe nas significações construídas nos espaços intersubjetivos, em que concorrem os processos imaginativos e afetivos.

\section{PÓS-GRADUAÇÃO E INSERÇÃO SOCIAL: QUESITO DE AVALIAÇÃO AINDA MAL DIMENSIONADO}

No documento de área da Psicologia de 2017, elaborado pela Comissão de Avaliação da Capes (Brasil, 2017), a inserção social é um dos quesitos considerados dentre os cinco que dimensionam a avaliação dos programas de pós-graduação (proposta do programa, produção intelectual, corpo docente e corpo discente). Ela aparece assim definida: 
O quesito Inserção Social, para a área de Psicologia, se refere às ações dos programas de pósgraduação que consistem na disseminação, transferência e/ou aplicação de conhecimentos e tecnologias produzidas pelos programas em benefício de diferentes setores sociais, visando minimizar ou solucionar problemas socialmente relevantes (p. 36).

Segundo o documento, a Capes ainda não tem critérios claros para a avaliação dessas açôes, assim como os programas que, frequentemente, inserem no relatório atividades voltadas ao público interno da universidade, ou desenvolvidas como projeto de extensão, ou ainda como resultado de estágios da graduação. Conforme consta da definição acima, a inserção social se caracteriza pela transferência de conhecimentos produzidos em pesquisas desenvolvidas no programa e têm, necessariamente, relação com a área de concentração do programa e com as linhas e projetos de pesquisa dos pesquisadores.

Embora a inserção social seja avaliada com critérios que the conferem os mesmos conceitos dos demais quesitos $(\mathrm{D}=$ deficiente, $\mathrm{F}=$ fraco, $\mathrm{B}=$ bom $\mathrm{e}$ $\mathrm{MB}=$ muito bom), seu peso na avaliação é diferente, pois não diminui a nota do programa, ainda que impeça sua progressão na avaliação. Ou seja, se o quesito inserção social obtiver $\mathrm{B}$, o conceito do programa poderá ser $\mathrm{MB}$, que equivale a 5, caso os outros quatro quesitos tenham MB. Entretanto, se o programa obtiver $\mathrm{MB}$ em todos os quesitos e indicadores, inclusive inserção social, e B em produção intelectual, por exemplo, o programa não será $\mathrm{MB}$ ou 5, mas 4. Longe de sugerir que se meçam ações dessa natureza, tampouco que as computem nas avaliações, quer-se apenas problematizar a excessiva valorização da produção intelectual bibliográfica, sobretudo em revistas, conferindo-se primazia a esse tipo de produção nos programas, em detrimento de ações que se voltem ao social e promovam mudanças em contextos sociais precariamente atendidos pelo Estado.

Ressalta-se, no entanto, que a ideia de se vincular a produção em pesquisas com diferentes setores sociais que deveriam se beneficiar dessas produçóes pode ser profícua, se nos voltamos ao campo das Ciências Humanas e Sociais, sobretudo à Psicologia. Essa acepção nos conduz, no entanto, a um outro questionamento: que tipo de produção? Que tipo de pesquisa? Qual a participação dos sujeitos supostos beneficiários na produção e resultados das pesquisas? Como essa inserção poderia se constituir em enfrentamento da desigualdade e em ações para a superação de sofrimento psicossocial? 


\section{A PERSPECTIVA TEÓRICO-METODOLÓGICA DA PESQUISA- INTERVENÇÃO:}

Em 1927, quando da escrita do Significado histórico da crise da Psicologia, Vigotski (2004) já chamava a atenção para a inadequação dos métodos utilizados na Psicologia, e sugeria que se tomasse outro caminho para a produção e sistematização da Psicologia como uma ciência geral (Vygotsky, 2004). Há tempos que a Psicologia que se afilia a uma perspectiva crítica vem problematizando a dimensão teórico-metodológica que tem utilizado na produção das pesquisas da área.

Baseados nos pressupostos de Vigotski (2004), de que a pesquisa deve focalizar o processo e não o produto, referindo-se claramente que o fenômeno investigado só poderá ser apreendido por uma análise histórica em que se busca compreender suas transformações ao longo de sua existência, o grupo de pesquisa que coordeno vem se questionando sobre as formas de acercamento das questôes que emergem no cotidiano em que atuamos.

Ao longo de nossas investigações e reflexões nos últimos anos, alinhados ao que preconiza Vigotski, temos nos dedicado a construir formas de investigação que nos possibilitem uma aproximação maior da realidade e sua compreensão, entendendo que, a depender do contexto e do fenômeno investigado, novos desenhos e estratégias metodológicos são necessários, sendo o método, portanto, a um só tempo, caminho e produto da investigação.

Fruto desse investimento, o que temos denominado de pesquisa-intervenção tem se constituído como processo/movimento que nos permite, de modo concomitante, construir compreensōes sobre a realidade e transformá-la, permanentemente (Souza, Dugnani, \& Reis, 2018).

Essa perspectiva/postura investigativa entende o pesquisador como participante da pesquisa-intervenção, pois se envolve nos processos de significação empreendidos nas relações intersubjetivas que caracterizam os contextos de investigação (Souza et al., 2018).

Em síntese, a pesquisa-intervenção visa, simultaneamente, a produzir conhecimento sobre os fenômenos investigados, elaborar métodos de acesso ao fenômeno e desenvolver práticas psicológicas comprometidas com a transformação das condições de vida de alunos, educadores e comunidade, ação necessária ante as condiçôes desiguais a que estão submetidos os estudantes de escolas públicas da periferia de grandes cidades, conforme se aborda no próximo tópico. 


\section{A ESCOLA PÚBLICA BRASILEIRA E A PERPETUAÇÃO DA DESIGUALDADE}

Arretche (2015), em livro que organiza sobre o tema da desigualdade em suas diversas dimensões, afirma que há, no mundo atual, "Múltiplas desigualdades: entre pobres e ricos, entre mulheres e homens, entre categorias e raças [. . . que se manifestam na renda, no acesso a serviços, na participação política" (p. 6). Ou seja, não é possível falar em desigualdade no singular, mas tomá-la como múltipla, complexa e também com várias determinaçôes.

Dessa perspectiva, é preciso superar a ideia de que a desigualdade se relaciona à pobreza, é estática e, uma vez superada, deixa de existir. Defende que uma abordagem mais precisa do tema seria tratar das "trajetórias das desigualdades", termo que preserva seu caráter de múltiplas determinações e em movimento. Essa acepção demanda considerar que a desigualdade representa e repercute várias situações e compreendê-la como tal permite ficar atento ao risco de naturalizá-la.

Sawaia (2009) entende a desigualdade como sofrimento ético-político, cuja gênese é social e histórica. Nesse sentido, a vivência desse sofrimento é permanente, assumindo a característica de "cronicidade de afetos tristes", afetando pessoas, grupos ou mesmo gerações. Essa dimensão que os afetos assumem na desigualdade vivida perenemente vai produzindo condições de vida cada vez mais opressoras, submetendo as pessoas a um assujeitamento em que abandonam a luta por direitos:

Desta forma, passa-se a ter medo do medo, ou seja, a ser duplamente amedrontado, duplamente angustiado. Angustiado pela situação social e angustiado com a própria angústia de fracassar e perder as forças conservadoras, culpabilizando-se por isso. Um processo que tende a se cronificar nas experiências da desigualdade como sentimento de desamparo (Sawaia \& Silva, 2019, p. 32).

As autoras chamam a atenção para o fato de que afetos como medo e esperança, por seu caráter conservador, produzem o padecimento do sujeito que se submete às condições de vida e desiste de agir para a superação dessa condição em nome de uma pretensa segurança. Nesse movimento, desistem da liberdade por terem minado seu poder de agir em direção à abertura de novas possibilidades de vida.

A compreensão da desigualdade como condição social e histórica e sua repercussão no sujeito como afecção que produz padecimento nos conduzem a pensar a escola e seu papel em sua produção.

No que concerne ao acesso à escola de ensino fundamental, é possível dizer que a desigualdade foi superada, uma vez que há vagas disponíveis para todos 
os alunos de 7 a 14 anos. Entretanto, qual a qualidade do ensino ofertado? Por que os anos finais do ensino fundamental são os que registram maior índice de distorção idade-série, abandono e evasão, segundo o Censo de 2018 (Instituto Nacional de Estudos e Pesquisas Educacionais Anísio Teixeira [INEP], 2018)?

Dado a se observar, também, é o índice de estudantes pretos e pardos na Educação de Jovens e Adultos (EJA), em que são imensa maioria (72,3\%) dos alunos (INEP, 2018). Por quê? Sabe-se que esses alunos são os que foram ficando para trás, nas salas de aulas, entrando para o grupo daqueles com distorção idade-série, distanciando-se cada vez mais das possibilidades de significação dos conteúdos ensinados, passando a integrar o grupo do absenteísmo, chegando ao abandono e à evasão. Esses são exemplos típicos de mudança de trajetória das desigualdades e que justifica o uso da expressão no plural: as desigualdades vão se constituindo em camadas; a impossibilidade de acesso à educação de qualidade é maior nos mais pobres, pretos e pardos, conforme explica Arretche (2015), ao nos chamar a atenção sobre o perigo de se naturalizar a desigualdade, caso não estejamos atentos a esse movimento, no caso, as desigualdades que caracterizam a qualidade da educação ofertada nas escolas públicas e privadas do país.

A esse respeito, Libâneo (2012) oferece uma explicação que corrobora os dados do Censo de 2018 (INEP, 2018): é fato que a quase totalidade das crianças e jovens de 7 a 14 anos tem vaga garantida nas escolas de ensino fundamental. Entretanto esses alunos não acessam o mesmo tipo de ensino. Para o autor, haveria uma escola de ricos e uma escola de pobres. Sustenta sua afirmação em análise das políticas educacionais do Brasil ao longo dos últimos 20 anos, em que identifica a existência do que denomina "dualismo perverso", cujas raízes remontam à reforma do ensino inglês, na década de 1980, sustentado nos princípios neoliberais, os quais, por sua vez, estariam em consonância com os acordos internacionais operados na esteira do movimento "Educação para Todos", que costurou acordo com o Banco Mundial para uma pretensa melhoria da educação.

Segundo o autor, esse movimento teve como marco

A Conferência Mundial sobre Educação para Todos, realizada em Jomtien, na Tailândia, em 1990, sob os auspícios do Banco Mundial, do Programa das Naçóes Unidas para o Desenvolvimento (PNUD), do Fundo das Naçôes Unidas para a Infância (UNICEF) e da Organização das Nações Unidas para a Educação e Cultura (UNESCO) (Libâneo, 2012, p. 12).

\footnotetext{
1 O censo de 2018 registra que, em 2014, houve cerca de 15 milhões de matrículas nos anos iniciais do ensino fundamental e, no ano de 2018, havia cerca de 12 milhões de matrículas nos anos finais. Mais de 3 milhões de estudantes, crianças e adolescentes, perderam-se pelo caminho. A taxa de distorção idade-série alcança $24,7 \%$ das matrículas dos anos finais do ensino fundamental. A maior diferença entre os sexos é observada no sexto ano do ensino fundamental, em que a taxa de distorção idade-série é de $31,6 \%$ para o sexo masculino e $19,2 \%$ para o feminino.
} 
Esse dualismo, segundo Libâneo (2012), seria extremamente eficiente na produção e manutenção da desigualdade social, pois justamente àqueles que mais necessitam estaria destinada uma educação de menor qualidade.

Parece haver, na produção e desenvolvimento de políticas educativas e nos discursos difundidos por alguns especialistas da educação, sobretudo aqueles sustentados por entidades financeiras, certa intencionalidade em propagar significações antagônicas sobre o que seria papel da educação escolarizada. Há desde visões que defendem a volta da educação tradicional e autoritária, que visa à razão e expulsa os afetos do contexto escolar, até a ideia de que a escola teria como função minimizar a desigualdade, acolhendo e assistindo à população carente (Libâneo, 2012).

Essas compreensões de como a educação se organiza no Brasil somadas aos baixos resultados dos alunos nas avaliações produzidas pelo governo, permitemnos afirmar que a escola não apenas produz desigualdade, mas também a perpetua, ao impedir que um enorme contingente de crianças e adolescentes avancem em seus processos de desenvolvimento, por não conseguirem se apropriar de conhecimentos complexos e construir novos e mais complexos recursos de ação e pensamento.

Um panorama dessa situação pode ser observado nos números do último Censo Escolar, publicado em 2018 (INEP, 2018). Segundo o levantamento realizado pelo INEP (Instituto Nacional de Estudos e Pesquisas Educacionais Anísio Teixeira), havia, em 2018, 48,6 milhões de alunos matriculados na educação básica no Brasil, nas redes pública e privada, com a maioria concentrada na rede pública $(81,7 \%)$ e somente $18,3 \%$ na rede privada. A rede pública atende a um número gigantesco de crianças e jovens, de 0 a 17 anos, 36,6 milhões, número sete vezes maior que a população da Finlândia (cuja educação é tomada, por alguns especialistas, como modelo a ser seguido pelo Brasil) (INEP, 2018).

Esses números nos ajudam a problematizar as desigualdades presentes nas escolas e apontar as contradições que caracterizam a educação no Brasil, submetida ao projeto neoliberal que oferece aos pobres que frequentam a escola pública uma educação centrada na assistência e confere às escolas a responsabilidade de atender a demandas para as quais seus profissionais não dispõem de saberes ou experiência. Cria ainda certa confusão, ao desviar a função da escola historicamente pensada para o ensino de conhecimentos socialmente elaborados. É segundo essa premissa que os professores são formados e os currículos estruturados.

A contradição que se quer apontar aqui é que a educação para o acolhimento também fracassa, incapaz de dar conta da diversidade e diferenças dos estudantes e de suas demandas. Ainda como razão do fracasso, há a falta de clareza dos 
educadores sobre as finalidades da educação que devem oferecer e a grande quantidade de alunos que formam o contingente do público da escola pública. Eis a contradição: a escola do acolhimento expulsa os alunos da escola, em um movimento que se apresenta como "repulsa à diferença", conforme afirmam Cunha e Dazzani (2016).

E então o Estado, que deveria garantir direitos aos quase 40 milhões de crianças e jovens, promovendo o acesso ao conhecimento e à cultura, condição para o desenvolvimento de funçôes psicológicas complexas que permitem ao sujeito pensar de modo mais ampliado, compreender suas condições de vida e suas possibilidades de transformá-las, faz-se presente por meio de políticas muito pouco efetivas, comprometendo o desenvolvimento de toda uma geração.

\section{A ESCOLA COMO FOMENTADORA DA SUPERAÇÃO DA DESIGUALDADE: O PAPEL DO CONHECIMENTO}

Segundo Vigotski (2010), o meio social é fonte de desenvolvimento do sujeito. Essa acepção está na base de nossa compreensão e defesa da escola como instituição social privilegiada na promoção do desenvolvimento de funções psicológicas superiores, visto ter como função privativa o ensino de saberes sistematizados, que favorecem o desenvolvimento do pensamento por conceito, necessário à compreensão mais ampliada da realidade pelo sujeito. É pela apropriação do conhecimento que o sujeito se torna capaz de dominar seu comportamento e se apropriar de modos de pensar mais elaborados e formas de linguagem que ampliam suas significações, as quais têm em sua base a imaginação, a um só tempo, resultado da mediação da cultura e mediatizante do processo de desenvolvimento psicológico. É nesse sentido que a escola pode se constituir como promotora da superação das desigualdades, justamente por possibilitar a visualização de novas possibilidades de futuro (Souza, 2016).

Ainda que políticas educativas perenes, caracterizadas como políticas de Estado com objetivos e metas de longo prazo, que não sucumbam a mudanças de governos, restituam à escola seu papel de fomentadora do desenvolvimento dos sujeitos que dela participam, como estudantes, profissionais ou comunidade, será necessário um grande esforço por parte de educadores e múltiplos profissionais no estabelecimento de princípios, objetivos, conteúdos e estratégias curriculares que contemplem a diversidade e as condiçóes desiguais de vida dos sujeitos, o que significa prever vários caminhos possíveis para os alunos, superando os currículos e propostas atuais que colocam uma única meta ou lugar ao qual 
todos os estudantes devem chegar ou atingir. Ou seja, a escola terá de enfrentar a complexidade que resulta da interação de sujeitos singulares, com desejos, interesses e objetivos diversos.

Atender à diversidade como forma de combater a desigualdade ou garantir direitos não significa, portanto, somente incluir os diferentes na escola, mas também, e principalmente, permitir que os sujeitos sejam diferentes no convívio escolar, no modo de se expressar, de sentir, de pensar, de ser, enfim. Na escola então se chega diferente e se sai dela diferente, mas todos com condições de responder aos desafios que o futuro vai impor-lhes, tendo condições de escolha e consciência de suas responsabilidades como sujeito social e histórico, visto terem se apropriado dos bens da cultura (Souza, 2016).

Fundamental nesse processo de desenvolvimento é a imaginação que, segundo Tateo (2016), é uma das mais importantes funçôes psicológicas superiores, por possibilitar ao homem "criar conceitos abstratos e tratá-los como coisas reais e de criar coisas reais e tratá-las como conceitos abstratos" (pp. 149-150). É ela que está na base do desenvolvimento do pensamento por conceito, função psicológica que permite ao sujeito se libertar do mundo empírico e acessar o passado e o futuro, o presente e o distante, o simples e o complexo, enxergando as condicionantes de um no outro.

A esse respeito, Sawaia, Albuquerque, e Bussarello (2018) contribuem para se avançar no aprofundamento da questão ao problematizarem a relação entre determinação e liberdade no processo dialético de constituição da subjetividade, em que a imaginação tem lugar de destaque. Entendem as autoras que a determinação do sujeito é ato criativo por ser mediada pela imaginação no processo de sua constituição como humano. Compreensão que coloca essas dimensões constitutivas do sujeito como unidade determinação-liberdade, assim como subjetividade-objetividade.

E entendemos que, nesse processo, a emoção, enlaçada à imaginação, tem papel fundamental, razão que nos conduz a defender a Arte, por seu caráter simbólico e de síntese do sentimento de dada época ou contexto, como instrumento psicológico que favorece a constituição do humano como unidade dialética, que concentra as tensões produzidas pela oposição e complementariedade entre a determinalidade do sujeito, como o que deve ser/fazer, e sua resistência ao determinado, de onde nasce sua liberdade (Souza, Petroni, \& Andrada, 2016; Sawaia \& Silva, 2019). Essa é a beleza que se esconde no processo mesmo do viver, e a relação com as expressões artísticas, no âmbito da apreciação ou do fazer, permite-nos acessá-la (Souza, Petroni, \& Dugnani, 2011). É sobre essa relação, que temos explorado sob o prisma da Psicologia da Arte, que trata o 
próximo tópico, em que se apresentam algumas proposições de Vigotski e se busca ampliar o diálogo com a Filosofia, a Literatura, a Arte e a Educação.

\section{ARTE E IMAGINAÇÃO NA ESCOLA: VIVÊNCIAS POTENTES NO ENFRENTAMENTO DO SOFRIMENTO PSICOSSOCIAL}

No Psicologia da Arte, livro da tese de doutoramento de Vigotski (1999), publicado em 1925, estão colocadas as bases do que o autor entende por emoção e sua relação com a Arte e a imaginação. Em uma de suas passagens, ele diz: "A arte é a mais importante concentração de todos os processos biológicos e sociais do indivíduo na sociedade, é um meio de equilibrar o homem com o mundo nos momentos mais críticos e responsáveis da vida" (Vigotski, 1999, pp. 328-329). Ou seja, destaca o potencial da Arte para integrar o homem em suas dimensões corporal e psicossocial. Radica nessa compreensão nossa experiência na relação com a Arte: não por acaso, perdemos a noção do tempo mergulhados em uma produção literária e nos sentimos em paz depois de viver os dramas dos personagens da história.

A explicação de Vigotski (1999) sobre a natureza da Arte corrobora essas acepções:

A verdadeira natureza da arte sempre implica algo que transforma, que supera o sentimento comum, e aquele mesmo medo, aquela mesma dor, aquela mesma inquietação, quando suscitadas pela arte, implicam algo a mais, acima daquilo que nelas está contido (p. 307).

São essas características, constituintes de sua natureza, que nos conduzem a tomar as expressões artísticas como instrumento psicológico potente na promoção da imaginação. Sua apreciação permite ao sujeito viver emoções que podem estar "escondidas", ou obscurecidas, e, ao vivê-las, elaborá-las, podendo sentilas de outro lugar, com outras compreensões, acima daquilo que as mantiveram cristalizadas na sustentação do medo ou da angústia, de paixões tristes, como afirma Espinosa (1957). Essas são condições em que encontramos muitas das pessoas que vivem na escola, sobretudo os alunos. A experiência relatada a seguir visa a transformá-las, pondo em evidência as possibilidades da imaginação e da criação como produtoras de potência de ação. 


\section{ALGUMAS INFORMAÇÕES SOBRE A PESQUISA- INTERVENÇÃO}

Apresentamos duas atividades realizadas com estudantes que tinham entre 16 e 18 anos, cursavam o segundo ano do ensino médio de uma escola pública da Rede Estadual de São Paulo, localizada na periferia de uma grande cidade do interior do Estado. A análise aqui apresentada toma como base dois encontros com os alunos, de um total de 16, realizados ao longo do ano de 2017, em que assistiram ao documentário "Sal da Terra", de Sebastião Salgado, e apreciaram fotografias de vários projetos do artista, relatados no documentário; e, no outro, em que foram expostas reproduções das pinturas de Sérgio Ricciuto Conte, um pintor italiano contemporâneo que vive no Brasil e produz uma pintura com características surrealistas e que se utiliza de vários elementos relacionados a jovens e livros.

Para a apreciação das fotografias e pinturas, além de convidar os estudantes a observarem as emoções e sentimentos que as expressões artísticas suscitavam, depois de alguns minutos apreciação, apresentávamos perguntas disparadoras, tais como: o que vocês veem?, o que essas imagens os fazem pensar?, que relações têm com as experiências de vocês? Após as discussões e reflexões feitas oralmente, no caso das fotografias, propôs-se aos estudantes a produção de uma história escrita, utilizando uma ou mais reproduções observadas.

\section{AS FOTOGRAFIAS}

As duas reproduçôes que deram origem às expressões dos estudantes que apresentamos a seguir são parte de dois projetos do fotógrafo Sebastiáo Salgado: uma mostra um campo de refugiados em Ruanda e consta da parte do livro Êxodos (Salgado, 2000), ${ }^{2}$ denominada: "A tragédia africana: um continente à deriva"; a outra mostra um menino solitário, muito magro, caminhando ao lado de um cachorro. Trata-se de garoto perdido de sua família após o massacre em Ruanda e consta do livro África (Salgado, 2007), em que explora o tema da desigualdade.

Quando eu vejo essas imagens, acredito que, quando qualquer pessoa vê, sente uma tristeza, um aperto no coração, uma angústia que nos toma conta. Essas pessoas que sofrem dessas situaçoes muitas vezes não são ajudadas, e isso lhes causa um grande sofrimento, ou seja, um sinal de desaprovação da própria humanidade! Nós temos que pensar: e se fosse eu, e se fosse com a minha família? Essas pessoas passam sua vida inteira nesses lugares desagradáveis,

2 "Este livro [Êxodos] conta a história da humanidade em trânsito. É uma história perturbadora, pois poucas pessoas abandonam a terra natal por vontade própria. Em geral, elas se tornam migrantes, refugiadas ou exiladas constrangidas por forças que não têm como controlar, fugindo da pobreza, da repressão ou das guerras. [. . . ] Viajam sozinhas, com as famílias ou em grupos. Algumas sabem para onde estão indo, confiantes de que as espera uma vida melhor. Outras estão simplesmente em fuga, aliviadas por estarem vivas. Muitas não conseguirão chegar a lugar nenhum” (Salgado, 2000, p. 7). 
lugares que é praticamente impossível de ter uma vida saudável. Não sei como terminar, me desculpe te fazer esperar, essa foi uma rima pra te alegrar, e nessas situações degradantes parar de pensar (Anônimo, 16 anos $-2^{\circ}$ ano noturno) (grifo do autor).

Observa-se, na expressão do adolescente, um claro movimento no modo de vivenciar a experiência de acessar as realidades de sofrimento expressas nas fotografias: por ser fotografia, parece inquestionável a veracidade das imagens e, portanto, das situações que o afetam sobremaneira. E então ele percebe que se tratam de situações que não somente o afetam, mas qualquer pessoa, despertando tristeza e angústia. E esse movimento que tem no centro a imaginação, enlaçada com a emoção (Sawaia, 2000), permite ao sujeito ampliar sua reflexão justamente pelas novas relações que constrói no âmbito do pensamento; pensar que poderia ser ele próprio a viver a situação, pensar que há pessoas que vivem em situação miserável a vida toda e nunca têm ajuda, até chegar à generalização da experiência, em que expressa o que seria a síntese de sua vivência: a desaprovação da própria humanidade. Segundo Vigotski (1999); "O sentimento é inicialmente individual, e através da obra de arte 'torna-se' social ou generaliza-se” (p. 308).

Mas as emoções que a fruição desperta são muito doloridas, e então parece que ele encontra uma saída: fazer uma brincadeira para interromper o curso do pensamento motivado por afetos tristes, movimento que parece corroborar a compreensão de Vigotski (1999) quando diz que "A arte parte de determinados sentimentos vitais mas realiza certa elaboração desses sentimentos [. . .] que consiste na catarse, na transformação desses sentimentos em sentimentos opostos, nas suas soluções" (p. 309).

Nesse processo, imaginação e emoção se imbricam, visto que o ato de fruir uma obra demanda a criação, visto que, nesse tipo de percepção/interpretação, não basta vivenciar o sentimento expresso na obra ou compreender seus significados, mas é preciso "superar criativamente o seu próprio sentimento" (Vigotski, 1999, p. 314). Também é possível destacar o processo reflexivo e dialético que "Anônimo" empreende na leitura das imagens, em que vai fazendo relaçóes a partir do que conhece, confrontando suas experiências, pondo em questão o social (outros) até chegar à própria humanidade, no caso, desumanidade, ou, em suas palavras, desaprovação da própria humanidade, termo criado por ele, derivado de sua imaginação e que parece conter certo adensamento do significado de desumanidade. 


\section{A PINTURA SURREALISTA}

O diálogo que apresentamos a seguir resulta da apreciação de pinturas do artista Sérgio Ricciuto Conte, de natureza surrealista, com vários elementos que remetem a leitura e a jovens em situações inusitadas. A imagem mostra um livro enorme, aberto, pairando no espaço em que se vê um céu azul atrás e, abaixo, um solo esverdeado com alguns pequenos pontos vermelhos. Sai do livro minúsculas gotinhas brilhantes que caem e se juntam aos pontinhos vermelhos no chão. Eis o que dizem os jovens: ${ }^{3}$

"Um livro."

“Tá saindo água do livro."

"Não, tá saindo a história!"

"Tá se desmanchando."

"Pra mim, é água."

"Para mim, parece água."

"O livro tá falando de uma história real e a história do livro tá indo pra realidade."

"Ó!!!” (e dão risada)

"Como?"

"Imaginação, cara!"

"Se isso aqui que tá caindo é neve e o livro tá em cima, o livro é uma nuvem? O livro tá representando uma nuvem? Porque tá caindo neve!"

"Ali embaixo podem ser florzinhas."

"Os pensadores têm a cabeça nas nuvens."

"As imagens estão mais difíceis hoje" (em relação às fotografias apreciadas nas semanas anteriores).

"Sei lá, é um negócio estranho. Tem que decifrar."

"Porque não tem um significado certo."

"É diferente de fotografia."

"São pinturas."

Fica muito evidente a potência da imaginação mobilizada pela Arte, no caso, de natureza surrealista, ou seja, que se utiliza de objetos conhecidos, do cotidiano 
dos sujeitos e os apresenta de modo inusitado. Na relação com esse tipo de expressão artística, em um primeiro momento, o sujeito vive um sentimento de estranheza. $\mathrm{O}$ modo como a pesquisadora encaminhou a apreciação põe em movimento os seus significados e sentidos expressos pelos sujeitos, que vão sendo compartilhados e rejeitados, sintetizados e ampliados, processo em que a imaginação reina soberana, chegando a ser citada por um participante: "Só a imaginação é capaz de me fazer construir uma ideia extremamente abstrata. O livro está falando de uma história real, e a história do livro está indo para a realidade".

Ela também mostra sua potência para mobilizar o outro e promover o sentimento e pensamento coletivos. É por esse processo que os estudantes chegam à abstração ao fim do diálogo, em que conceituam a pintura a partir da relação com a fotografia: "Não têm um significado certo", "É diferente de fotografia", "São pinturas".

As expressões dos jovens no diálogo acima parecem ilustrar o que diz Vigotski (1999), ao afirmar que a Arte amplia nossa opiniāo sobre certo campo de fenômenos e nos conduz a observá-lo de outro modo, em um processo que culmina com a generalização de fatos dispersos.

Ao buscar defender a especificidade da Psicologia da Arte, Vigotski (1999) faz uma diferenciação entre a experiência comum, vivida no cotidiano, e a experiência estética, vivida na relação com a Arte. Reconhece que a percepção tem papel importante na experiência estética, assim como a emoção elementar. No entanto confere maior centralidade ao sentimento ${ }^{4}$ (que seria função superior) e à imaginação. Para o autor, é no cruzamento dos dois, sentimento/emoção e imaginação, que se pode compreender a Psicologia da Arte.

\section{PARA FINALIZAR, ALGUNS DESTAQUES}

Parece que o que se anuncia como síntese das reflexões apresentadas neste artigo, em que se defende a escola em sua potência para perpetuar ou superar a desigualdade, é um grande paradoxo: o fato de a igualdade e equidade estarem dispostas nos currículos como princípios que devem estar na base de todas as ações e objetivos da educação não tem favorecido ações capazes de enfrentar a grande desigualdade que caracteriza as condições de escolarização a que estão submetidos os alunos de escolas públicas no Brasil. Se tomarmos os currículos como políticas educativas de Estados e Municípios, restaria a constatação de que

\footnotetext{
4 Em várias passagens de sua obra, Vigotski utiliza a expressão "sentimento" como sinônimo de emoção. Entretanto, nesta passagem retirada do Psicologia da Arte (Vigotski, 1999, p. 249), usa emoção para referir-se à função elementar, do âmbito do biológico e sentimento para função psicológica superior, mediada, cultural.
} 
políticas públicas, ainda que fundamentais, não são suficientes para enfrentar a complexidade que caracteriza as desigualdades a que estão submetidas as camadas mais pobres de nosso país.

Concorre para o acirramento da questão o desconhecimento ou incompreensão de educadores e profissionais afins sobre o significado de desigualdade, visto a não problematização do termo no interior das escolas, e sobre o papel da educação na promoção de sua superação, que equivaleria promover o ensino de conhecimentos formais e o acesso à cultura, entendida como produção humana que congrega linguagens, emoções, valores, etc., de modo a favorecer o desenvolvimento de funções psicológicas superiores como recursos para as ações e pensamentos do sujeito, no presente e no futuro.

O que se observa e ratifica essa compreensão é que, via de regra, a escola entende que atender à diversidade é aceitar/acolher todos, o que o faz, ainda que por força de lei. Entretanto não extrapola essa compreensão para o modo como se organiza, o ensino se desenvolve, os processos são avaliados ou os grupos convivem. Tampouco se voltam ao projeto político-pedagógico, ao currículo ou planejamento de ensino para problematizar o modo como a diversidade é contemplada. E ainda, não se reflete sobre as normas e valores que guiam as ações. Ou seja, "que entrem todos", mas o ato mesmo de acolher já contém, potencialmente, a repulsa e exclusão, "não serão todos que ficarão", e ainda que fique a maioria, "poucos se apropriarão" dos conhecimentos escolarizados.

No capítulo Arte e vida, do livro Psicologia da Arte, referindo-se a Arte e trabalho, Vigotski (1999) menciona que, na Antiguidade, alguns povos acreditavam que a atividade de cantar era um acompanhamento necessário no desenvolvimento de trabalhos pesados, pois, além de organizar as ações, constituindo-as como coletivas, dava vazão à tensão, por vezes angustiante. Nesse sentido, a Arte se justifica não somente em atividades em que os esforços se combinam, mas também permite que o cansaço de um encontre alívio no cantar com os outros. Para o autor, "A arte surge como um forte instrumento de luta pela existência" (Vigotski (1999, p. 310, grifo do autor). E a Psicologia pode começar a contribuir, escutando o que os outros podem necessitar, ainda que não possam ou consigam expressar; parece que a Arte tem esta capacidade. 


\section{REFERÊNCIAS}

Arretche, M. (Org.). (2015). Trajetórias das desigualdades: como o Brasil mudou nos últimos cinquenta anos. São Paulo: Unesp.

Brasil. (2010). Coordenação de Aperfeiçoamento de Pessoal de Nível Superior. Plano Nacional de Pós-Graduação - PNPG 2011-2020. Brasília: Capes. Recuperado a partir de https://www.capes.gov.br/plano-nacional-de-posgraduacao

Brasil. (2017). Coordenação de Aperfeiçoamento de Pessoal de Nível Superior. Diretoria de Avaliação, Comissão de Avaliação da Area de Psicologia. Brasília: Capes.

Cunha, E. O. \& Dazzani, M. V. M. (2016). Da repulsa da escola à diferença: historicizando raízes, perspectivando saídas. In M. V. M. Dazzani \& V. L. T. Souza (Org.), Psicologia escolar crítica: teoria e prática nos contextos educacionais. (pp. 57-75). Campinas: Átomo e Alínea.

Espinosa, B. (1957). Ética. L. Xavier (Trans.). (3a ed.). São Paulo: Atenas.

Instituto Nacional de Estudos e Pesquisas Educacionais Anísio Teixeira. (2018). Resumo técnico: Censo da Educação Básica - 2018. Brasília: INEP.

Libâneo, J. C. (2012). O dualismo perverso da escola pública brasileira: escola do conhecimento para os ricos, escola do acolhimento social para os pobres. Educação e Pesquisa, 38(1), 13-28.

Salgado, S. (2000). Exxodos. São Paulo: Companhia das Letras.

Salgado, S. (2007). África. Colônia: Taschen.

Sawaia, B. B. (2000). A emoção como lócus de produção do conhecimento: uma reflexão inspirada em Vygotsky e no seu diálogo com Espinosa. In Anais da 3 Conferência de Pesquisa Sociocultural: cultura a dimensão psicológica e a mudança histórica e cultural. Campinas: Faculdade de Educação. Recuperado a partir de https://www.fe.unicamp.br/eventos/br2000/cult4.htm

Sawaia, B. B. (2009). Psicologia e desigualdade social: uma reflexão sobre liberdade e transformação social. Psicologia \& Sociedade, 21(3), 364-372.

Sawaia, B. B., Albuquerque, R., \& Bussarello, F. R. (2018). Afeto e comum: reflexóes sobre a práxis psicossocial. São Paulo: Alexa. 
Sawaia, B. B., \& Silva, D. N. H. (2019). A subjetividade revolucionária: questôes psicossociais em contexto de desigualdade social. In G. Toassa, T. M. C. Souza, \& D. J. S. Rodrigues (Org.), Psicologia sócio-histórica e desigualdade social: do pensamento à práxis. (pp 23-42). Goiânia: Imprensa Universitária.

Souza, V. L. T. (2016). Arte, imaginação e desenvolvimento humano: aportes à atuação do Psicólogo na escola. In M. V. M. Dazzani \& V. L. T. Souza (Org.), Psicologia escolar crítica: teoria e prática nos contextos educacionais. (pp. 77-94). Campinas: Átomo e Alínea.

Souza, V. L. T., Dugnani, L. A. C., \& Reis, E. C. G. (2018). Psicologia da arte: fundamentos e práticas para uma ação transformadora. Estudos de Psicologia, 35 (4), 375-388.

Souza, V. L. T., Petroni, A. P., \& Andrada, P. C. (2016). A Psicologia da arte e a promoção do desenvolvimento e da aprendizagem: intervençôes em contextos educativos. São Paulo: Loyola.

Souza, V. L. T., Petroni, A. P., \& Dugnani, L. A. C. (2011). A arte como mediação nas pesquisas e intervenção em Psicologia escolar. In R. S. L. Guzzo \& C. M. Marinho-Araújo (Orgs.), Psicologia escolar: identificando e superando barreiras. (pp. 261-285). Campinas: Átomo e Alínea.

Tateo, L. (2016). What imagination can teach us about higher mental functions. In J. Valsiner, G. Marsico, N. Chaudhary, T. Sato \& M. V. Dazzani (Eds.), Psychology as the science of human being: the Yokohama Manifesto. (pp. 149164). Berlin: Springer.

Vigotski, L. S. (1999). Psicologia da arte. P. Bezerra (Trad.). São Paulo: Martins Fontes.

Vigotski, L. S. (2004). O significado histórico da crise na Psicologia. In L. S. Vigotski, Teoria e método em Psicologia. C. Berliner (Trad.). (pp. 201-417). São Paulo: Martins Fontes.

Vigotski, L. S. (2010). Quarta aula: a questão do meio na pedologia. M. P. Vinha (Trad.). Psicologia USP, 21, 681-701. 